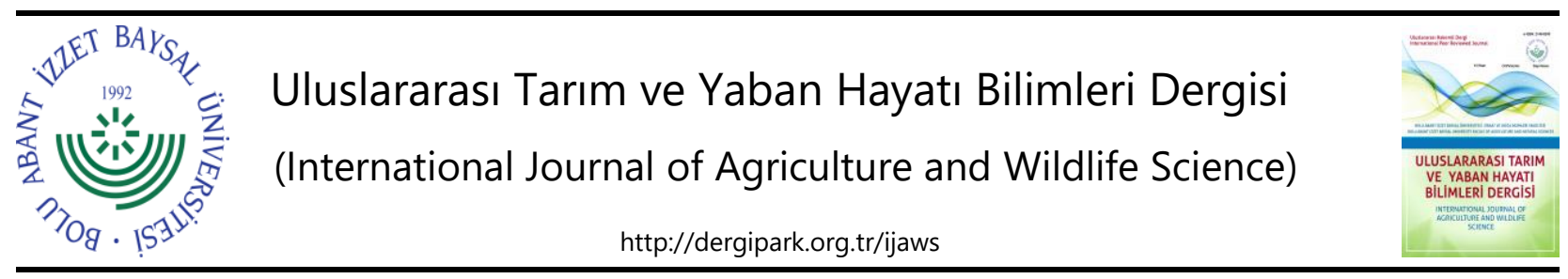

Araştırma Makalesi

\title{
Anaçların ‘Deveci’ Armudunun Verim Özellikleri Üzerine Etkisi
}

\author{
Ahmet Öztürk \\ Ondokuz Mayıs Üniversitesi, Ziraat Fakültesi, Bahçe Bitkileri Bölümü, Samsun \\ Geliş tarihi (Received): 17.08.2021 Kabul tarihi (Accepted): 18.10.2021
}

\section{Anahtar kelimeler:}

Armut, meyve ağırlığı, meyve sayısı, verim, kümülatif verim

\section{*Sorumlu yazar \\ ozturka@omu.edu.tr}

Özet. Modern meyve yetiştiriciliğinde kullanılan anaçlar üzerlerine aşılanan çeşitlerin büyüme, verim ve meyve kalitesini farklı şekillerde etkilemektedir. Bu çalışma ile farklı anaçlar (Quince BA-29, Quince MC ve armut çöğürü) üzerine aşıı Deveci armut çeşidinin 2013-2016 yıllarına ait verim özelliklerinin belirlenmesi amaçlanmıştır. Araştırmada verim özelliklerinden meyve ağılığı (g), meyve sayısı (adet bitki $\left.{ }^{-1}\right)$, bitki başına verim $\left(\mathrm{kg}\right.$ bitki-1) , gövde kesit alanına verim $\left(\mathrm{kg} \mathrm{cm}^{-2}\right)$, taç hacmine verim $\left(\mathrm{kg} \mathrm{m}^{-3}\right)$ ve dekara verim $\left(\mathrm{kg} \mathrm{da}^{-1}\right)$ incelenmiştir. İncelenen verim özellikleri üzerine anaçların önemli etkilerinin olduğu belirlenmiştir. Ayrıca meyve ağırlığı hariç incelenen diğer özellikler bakımından araştırma yılları arasında da önemli farklılıkların olduğu saptanmıştır. Meyve verim özellikleri üzerine ayva klon anaçlarının etkisi armut çöğür anacına göre daha yüksek olmuştur. Araştırmada meyve ağırığı (g), bitki başına verim ( $\left.\mathrm{kg} \mathrm{bitki}^{-1}\right)$ ve dekara verimin $\left(\mathrm{kg} \mathrm{da}^{-1}\right)$ BA-29 ayva klon anacında en yüksek, armut çöğür anacında ise en düşük olduğu belirlenmiştir. Gövde kesit alanına verim $\left(\mathrm{kg} \mathrm{cm}^{-2}\right)$ ve taç hacmine verimin $\left(\mathrm{kg} \mathrm{m}^{-3}\right) \mathrm{MC}$ ayva klon anacı üzerine aşılı bitkilerde yüksek olduğu belirlenmiştir. Araştırma sonucunda incelenen anaçlarla ilgili araştırmanın daha uzun süre devam ettirilerek kıyaslanması tavsiye olunmaktadır.

\section{The Influence of Rootstocks on Yield Characteristics of 'Deveci' Pear}

\section{Keywords:}

Pear, fruit weight, fruit number, yield, cumulative yield

\begin{abstract}
Rootstocks used in modern fruit growing affect the growth, yield and fruit quality of the cultivar grafted on them in different affects. This study was aimed to determine the effect of 'Deveci' pear cultivar grafted on different rootstocks (Quince BA-29, Quince MC and pear seedlings) on the yield characteristics among the 2013-2016 years. The fruit weight $(\mathrm{g})$, fruit number (pieces plant ${ }^{-1}$ ), yield per plant $\left(\mathrm{kg} \mathrm{plant}^{-1}\right)$, yield per stem cross-sectional area $\left(\mathrm{kg} \mathrm{cm}^{-2}\right)$, yield per crown volume $(\mathrm{kg}$ $\mathrm{m}^{-3}$ ) and yield per decare $\left(\mathrm{kg} \mathrm{da}^{-1}\right)$ were examined as yield characteristics in the study. Rootstocks have significantly effects on the examined yield characteristics. In addition, there were significant differences between the research years in terms of other examined yield characteristics except for fruit weight. The effect of the quince clonal rootstocks on fruit yield characteristics was higher than that of the pear seedling rootstock. In the study, the fruit weight $(\mathrm{g})$, yield per plant $\left(\mathrm{kg} \mathrm{plant}^{-1}\right)$ and yield per decare $\left(\mathrm{kg} \mathrm{da}^{-1}\right)$ were highest in the BA-29 quince clonal rootstock and the lowest in the pear seedling rootstock. The yield efficiency $\left(\mathrm{kg} \mathrm{cm}^{-2}\right)$ and yield per crown volume $\left(\mathrm{kg} \mathrm{m}^{-3}\right)$ were higher in the plants grafted on the $\mathrm{MC}$ rootstock. As a result of the study, it is recommended that the research related to the rootstocks examined is continued for a longer period and compared.
\end{abstract}




\section{GiRiş}

Armut ılıman iklim meyve türleri içerisinde elmadan sonra Dünyada en çok üretilen ve tüketilen yumuşak çekirdekli meyve türüdür (Özçağıran ve ark., 2005). Türkiye'de, elmadan sonra en fazla üretilen yumuşak çekirdekli meyve türü olan armut ülkemizin hemen hemen her yerinde yetiştirilmektedir. Türkiye'de ekonomik olarak yetiştiriciliği yapılan en yaygın armut türü $P$. communis olup Pyrus pyrifolia da yetiştirilmektedir (Ercişli, 2004; Özçağıran ve ark., 2005).

Ticari armut üretiminde vejetatif olarak çoğaltılan çeşitli ayva ve armut klon anaçları ile generatif armut anaçları kullanılmaktadır. Meyve yetiştiriciliğinde anaçlar üzerlerine aşılanan çeşidin büyüme ve gelişmesi yanında meyve irilik ve kalitesini de önemli derecede etkilemektedir (Webster, 1998; Jackson, 2003). Armut üretiminde meyve kalitesini artırmaları yanında, verimde erkencilik sağlamaları, budama, ilaçlama ve hasat gibi kültürel işlemlerin kolay yapılması ve ağaç büyüklüğünü çöğür anaçlara göre küçültmesi nedeniyle ayva ve armut klon anaçlarının kullanımı önerilmektedir (Bell ve ark., 1996; Stern ve Doron, 2009; Francescatto ve ark., 2010). Bu anaçlar içerisinde genellikle armut klon ve çöğür anaçları ayva klon anaçlarına göre daha güçlü bir gelişme göstermekte olup dikim mesafeleri daha geniştir (Bell ve ark., 1996; Özçağıran ve ark., 2005; Hancock ve Lobos, 2008). Ayrıca çöğür anaçları kuvvetli büyümenin yanında verime yatma yaşını geciktirmekte ve bazen de periyodisiteye neden olabilmektedir (Özçağıran ve ark., 2005). Dünya armut üretiminde birim alana daha yüksek verim alan Arjantin, A.B.D, Şili, Hollanda, Belçika ve İtalya gibi ülkelerde ticari armut bahçeleri genellikle Pyrus ve Cydonia klon anaçlarına aşılı armut çeşitlerine ait fidanlar ile kurulmaktadır. Armut ağaçlarında aşırı büyümeyi kontrol etmek, verimin erkenciliği ve her yıl düzenli verim almak amacıyla özellikle Pyrus communis çeşitlerinde armut klonları ile farklı bir cinsten olan ayva klonları (Cydonia oblonga L.) anaç olarak kullanılmaktadır (Browning ve Watkins, 1991; Webster, 2002; Jackson 2003; Francescatto ve ark., 2010).

Ülkemizde yaklaşık 23.2 milyon ton olan meyve üretiminin yaklaşık 5.1 milyon tonunu yumuşak çekirdekli meyve türleri oluşturmaktadır. Yumuşak çekirdekli meyve türleri içerisinde 545.569 tonluk üretim ile armut \%10.7'lik paya sahiptir (TÜiK, 2021). 2019 yılı FAO verilerine göre yaklaşık 1.4 milyon hektarlık alanda 23.9 milyon ton olan Dünya armut üretiminde Türkiye 530.723 tonluk armut üretimi ve bu üretimdeki \%2.2'lik pay ile Çin, Arjantin ve A.B.D'den sonra 4. sırada yer alan önemli bir üretici ülke konumundadır (FAO, 2021). Türkiye'de armut üretiminde yaygın olarak kullanılan "Deveci", "Santa Maria" ve "Williams" gibi çeşitlerle Türkiye'de armut üretimi her geçen yıl artmaktadır. Türkiye armut üretiminin yaklaşık \%20'sini oluşturan 'Deveci' armut çeşidi, Anadolu menşeli, yüksek meyve kalitesi, üretim ve depolama kapasitesiyle Türkiye'de son yıllarda popülerlik kazanan kışık en iyi armut çeşitlerindendir. 'Deveci' çeşidi yüksek meyve kalitesi ve uzun süreli muhafazaya uygunluğu dolayısıyla ihracatta önemli pay alan ve getirisi yüksek bir çeşittir.

Meyve ağaçlarının vejetatif büyümesinin, meyve veriminin, dikim sıklığının ve bahçe yönetiminin kontrolünü sağlanmasında en önemli stratejilerden birisi de doğru anaç seçimidir (Webster, 2002). Ülkemiz armut üretiminde önemli bir yeri olan 'Deveci' armudunun meyve verim ve kalitesinin artırılmasında uygun anaç seçimi hem üreticilerin maksimum gelir elde etmeleri hem de tüketicilerin kaliteli ürün tüketebilmeleri açısından oldukça önem arz etmektedir. Ayrıca bu çeşitte uygun yetiştirme tekniği ve anaç seçimi yapılmadığında istenilmeyen irilikte meyveler (aşırı iri ya da çok küçük) ve kabuk pürüzlülüğü ile verimde azalmalar meydana gelmektedir.

Bu çalışmanın amacı, 'Deveci' armut çeşidinin meyve verim özellikleri üzerine farklı anaçların etkilerini ortaya koymak ve yetiştiricilik için uygun anacı belirlemektir.

\section{MATERYAL VE METOT}

\section{Materyal}

Bu araştırma BA-29 ve MC ayva klon anacı ile armut çöğür anacı üzerine aşıı Deveci çeşidine ait 1 yaşı fidanlarla 2010 yılında kurulan üretici bahçesinde (41⒉' K; 36¹0' D; rakım 182 m) 2013-2016 yıllarında yürütülmüştür. Araştırmanın yürütüldüğü Samsun ili yazları sıcak ve nemli, kışları ise serin bir iklime sahiptir. Yağışlar en çok sonbaharın sonlarında ve kışın başlarında görülür. Samsun'un uzun yıllar iklim verilerine göre ortalama maksimum sıcaklık $26,2^{\circ} \mathrm{C}$; ortalama minimum sıcaklık $3.3^{\circ} \mathrm{C}$ ve ortalama yıllık sıcaklık $14.1^{\circ} \mathrm{C}$ dir (MGM, 2021). Araştırma arazisinde $20 \mathrm{~cm}$ den alınan toprak örneklerinde yapılan toprak analizine göre deneme alanı toprağı \%83 kil, düşük kireç (\%0.50), tuzsuz (\%0.105), $\mathrm{pH}(6.6)$, fosfor $\left(63.2 \mathrm{~kg} \mathrm{da}^{-1}\right)$, potasyum (236 kg da-1) ve yüksek organik madde (\%5.76) içeriğine sahiptir. 


\section{Yöntem}

Araştırmada BA-29 ve MC ayva (Cydonia oblonga) ve yerel yabani armut genotipinden (Pyrus communis L.) elde edilen çöğür anaç üzerine aşılı 'Deveci' çeşidine ait 1 yaşlı fidanlar kullanılmıştır. BA-29 ve MC anaçları üzerine aşılı fidanlar $3.5 \mathrm{~m}$ x $1.2 \mathrm{~m}$ (238 ağaç da $\left.^{-1}\right)$, çöğür üzerine aşılı fidanlar $4 \mathrm{~m}$ x $4 \mathrm{~m}$ aralıklarla (62 ağaç da-1) dikilmiş olup fidanlar modifiye lider sisteme göre budanmışlardır. Ayva anaçlarına aşılanan bitkiler, destek sistemine 0.5, 1.0 ve 1.5 m'de üç telden bağlandı, çöğürlere destek sistemi uygulanmadı. Ağaçlar her yıl düzenli olarak budanmışlardır. Sulama damla sulama sisteminde basınç dengeleyici damlatıcılar ile $1.20 \mathrm{~m}$ aralıklarla sıra başına bir boru olacak şekilde sıralar boyunca yerleştirilmiştir. Bitkinin su ihtiyacına göre bir hafta aralıklarla sulama yapılmıştır. Bitkilere NPK içerikli gübreler bitkilerin gelişimine bağlı olarak (yılda 40N - $10 \mathrm{P}_{2} \mathrm{O}_{5}-60 \mathrm{~K}_{2} \mathrm{O}^{\prime} \mathrm{ya}$ kadar) sulama sistemiyle uygulanmıştır. Yabancı ot kontrolü düzenli olarak yapılmıştır.

Araştırmada her bir anaca ait her ağaçtaki meyveler sayılarak bitki başına meyve sayısı belirlenmiştir. Her tekerrürde ağaçların iyi güneş gören kısımlarından rastgele 30 meyve örneği toplanmış ve bu meyvelerin ağırlığı 0.01 g'a duyarlı dijital terazi ile (CAMRY L-500) belirlenmiştir. Anaçlara göre her tekerrürdeki bitkilerin dijital kumpasla (Mitutoyo CD-20CPX) aşı noktasından $20 \mathrm{~cm}$ yukarıdan gövde çapı (mm) ölçülerek gövde kesit alanı $\left(\mathrm{cm}^{2}\right)$; taç yüksekliği $(\mathrm{m})$, taç eni $(\mathrm{m})$ ve taç boyu $(\mathrm{m})$ ölçülerek taç hacmi $\left(\mathrm{m}^{3}\right.$ ) hesaplanmıştır (Kosina, 2003; Stern ve Doron, 2009). Araştırmada meyve ağırlığı (g), bitki başına meyve sayısı (adet bitki ${ }^{-1}$ ), bitki başına verim (kg bitki $\left.{ }^{-1}\right)$, gövde kesit alanına düşen verim $\left(\mathrm{kg} \mathrm{cm}{ }^{-2}\right)$, taç hacmine düşen verim $\left(\mathrm{kg} \mathrm{m}^{-3}\right)$ ve dekara verim $\left(\mathrm{kg} \mathrm{da}{ }^{-1}\right)$ belirlenmiştir (Kosina, 2003; Stern ve Doron, 2009; İkinci ve ark., 2014; Pasa ve ark., 2017).

Araştırma 4 tekerrürlü ve her tekerrürde 5 ağaç olacak şekilde tesadüf blokları deneme desenine göre yürütülmüştür. Elde edilen veriler IBM SPSS 21.0 programı (SPSS Inc. Chicago, ABD) kullanılarak analiz edilmiş, ortalamalar arasındaki farklılıklar Duncan çoklu karşılaştırma testi ile \%5 ( $p>0.05)$ olasılık düzeyine göre belirtilmiştir.

\section{BULGULAR VE TARTIŞMA}

'Deveci' armudunda farklı anaçların meyve ağırlığı üzerine olan etkisi Çizelge 1'de verilmiştir. Meyve ağırlığı BA-29 anacı üzerine aşılanan bitkilerde en yüksek (258.56 g) iken, bunu MC (176.66 g) ve Çöğür (145.51 g) anaçları takip etmiştir. Araştırma yıllarında 2016 yılı dışında anaçlar arasında meyve ağırlığı bakımından önemli farkılıklar tespit edilmiştir. Araştırma yılları arasında meyve ağırlığı bakımından farklılık tespit edilmemiştir (Çizelge 1). BA29 üzerine aşılı 'Deveci' çeşidinde meyve ağırlığının Erdem ve Öztürk (2012) 241.0-243.8 g, Küçüker ve ark. (2015) 241.0-282.8 g, Uysal ve ark. (2015) 277.10-296.58 g arasında değiştiğini bildirmişlerdir. 'Forelle' armut çeşidinin meyve ağırlığı üzerine kullanılan anaçların etkisinin önemli olduğu ve Quince A ayva klon anacı üzerine aşılı bitkilerin meyve ağırlığının diğer anaçlardan daha yüksek olduğu bildirilmiştir (du Plooy ve van Huyssteen, 2000). Cabrera ve ark. (2015) farklı anaçlar üzerine aşılı 'Williams' armut çeşidinde anaçların meyve ağırlığı üzerine etki ettiğini, meyve ağırlığının BA-29 üzerinde diğer anaçlardan daha yüksek olduğunu bildirmişlerdir. Farklı anaçlar üzerine aşılı 'Conference' armut çeşidinde meyve ağırlığı üzerine anaçları etkisinin önemli olduğu ve meyve ağırlığının 151.1-207.9 g arasında değiştiği vurgulanmıştır (Iglesias ve Asin, 2005). 'Shahmiveh' armut çeşidinde en yüksek meyve ağırlığını BA-29 ayva klon anacı üzerine aşılı bitkilerden elde ettiğini bildiren Askari-Khorosgani ve ark. (2019) meyve ağırlığı üzerine anaçların etkisinin önemli olduğunu vurgulamıştır. Belirtilen çalışmalardan da görüleceği üzere anaçların üzerine aşılanan çeşidin meyve ağırlığını etkilediği görülmektedir. Bu etkinin anacın büyüme gücü, çeşidin genetik yapısı ve yetiştirme koşullarından da kaynaklanabileceğini söyleyebiliriz. Nitekim yapılan çalışmalarda diğer meyve türlerinde de olduğu gibi armut yetiştiriciliğinde kullanılan anaçların da meyve ağırlığı üzerine etki ettiği bildirilmektedir (Jackson, 2003; Kosina, 2003; Urbina ve ark., 2003; Iglesias ve Asin, 2005; Stern ve Doron, 2009; Iglesias ve Asin, 2011; Öztürk ve Öztürk, 2014; Pasa ve ark., 2017; Askari-Khorosgani ve ark., 2019; Meszaros ve ark., 2019). Araştırmadan meyve ağırlığı ile ilgili elde edilen sonuçların önceki çalışmalarla uyumlu olduğunu söyleyebiliriz.

Çizelge 1. Farklı anaçların 'Deveci' armut çeşidinde meyve ağırlığı (g) üzerine etkileri.

Table 1. The effect of rootstocks on fruit weight $(g)$ of 'Devecei' pear cultivar.

\begin{tabular}{lllll}
\hline \multirow{2}{*}{ Anaçlar } & \multicolumn{4}{c}{ Yıllar } \\
\cline { 2 - 5 } Ortalama \\
\hline BA-29 & $\mathbf{2 0 1 3}$ & $\mathbf{2 0 1 4}$ & $\mathbf{2 0 1 5}$ & $\mathbf{2 0 1 6}$ \\
MC & $319.18 \mathrm{a}$ & $255.77 \mathrm{a}$ & $252.13 \mathrm{a}$ & $207.17 \mathrm{a}$ \\
Çöğür & $137.48 \mathrm{~b}$ & $186.40 \mathrm{~b}$ & $196.37 \mathrm{ab}$ & $186.40 \mathrm{a}$ \\
\hline Ortalama & $125.20 \mathrm{~b}$ & $121.70 \mathrm{c}$ & $165.67 \mathrm{~b}$ & $169.47 \mathrm{a}$ \\
\hline
\end{tabular}

*: Aynı sütunda aynı harfle gösterilen anaç ortalamaları arasındaki fark önemli değildir ( $P>0.05)$.

**: Aynı satırda aynı harfle gösterilen yıl ortalamaları arasındaki fark önemli değildir $(P>0.05)$. 
Farklı anaçların 'Deveci' armudunda bitki başına meyve sayısı üzerine etkisinin istatistiksel olarak önemli olduğu belirlenmiştir. Bitki başına ortalama meyve sayısının ayva anaçlarında armut çöğür anacından daha yüksek olduğu saptanmış olup en yüksek meyve sayısı MC ve BA-29 (25.83 adet ve 25.25 adet) anaçları üzerine aşılı bitkilerden, en düşük ise çöğür üzerine aşılı bitkilerden (12.25 adet) elde edilmiştir. Araştırma yılları arasında da bitki başına meyve sayısı bakımından farklıığın olduğu tespit edilmiştir. Araştırmada kümülatif meyve sayısının MC ve BA-29 (103.3 adet bitki ${ }^{-1}$ ve 101.0 adet bitki ${ }^{-1}$ ) anaçları üzerine aşılı bitkilerde çöğür (49.0 adet bitki ${ }^{-1}$ ) üzerine aşılanandan daha yüksek olduğu saptanmıştır (Çizelge 2). Deneme süresince yıllara ve anaçlara göre değişmekle birlikte bitki başına meyve sayısında artış meydana gelmiştir. Araştırmada meyve sayısının az olduğu ilk yıllarda meyve ağırlığının daha yüksek olduğu, meyve sayısındaki artışa bağlı olarak meyve ağırlığının da azaldığı tespit edilmiştir (Şekil 1). BA-29 üzerine aşılı 'Rocha' armut çeşidinde bitki başına meyve sayısının yıllara göre değiştiğini bildiren Sete ve ark. (2019) bitki başına ortalama meyve sayısının araştırmanın ilk yıllında 28-33 adet, son yılında ise 28-66 adet arasında değiştiğini bildirmişlerdir. Ayrıca araştırıcılar bitki başına meyve sayısının üretim yıllarına göre arttığını, meyve sayısındaki artışa paralel olarak yıllara göre ortalama meyve ağırlığının da azaldığını vurgulamışlardır. Meyve sayısındaki artışa bağı olarak meyve ağılığında meydana gelen azalmayı bitkinin depoladığı besin maddelerinin bitki üzerindeki meyveleri beslemek için harcama kapasitesine bağlanabilir. Bodur anaçlarda vejetatif ve generatif gelişme kuvvetli anaçlara göre daha dengede olmaktadır (Jackson, 2003; Pasa ve ark., 2017). Bu dengeden dolayı bitki depo maddelerini öncelikle üzerindeki açan çiçeklerin meyve bağlamasına ve bunlardan oluşan meyvelerin beslenmesine harcamaktadır. Dolayısıyla meyve sayısında meydana gelen artışın bitkinin gelişme gücüne bağlı olarak harcanan depo maddelerinin sınırlı olması nedeniyle meyve ağırlığında azalmaya neden olabileceği söylenebilir.

Çizelge 2. Farklı anaçların 'Deveci' armut çeşidinde bitki başına meyve sayısı (adet bitki-1) üzerine etkileri. Table 2. The effect of rootstocks on fruit number per plant (number plant ${ }^{-1}$ ) of 'Devecei' pear cultivar.

\begin{tabular}{|c|c|c|c|c|c|c|}
\hline \multirow{2}{*}{ Anaçlar } & \multicolumn{4}{|c|}{ Yıllar } & \multirow{2}{*}{ Ortalama } & \multirow{2}{*}{$\begin{array}{l}\text { Kümülatif meyve sayısı } \\
(\text { adet bitki-1) }\end{array}$} \\
\hline & 2013 & 2014 & 2015 & 2016 & & \\
\hline BA-29 & $10.67 b$ & $18.33 \mathrm{a}$ & $30.00 \mathrm{a}$ & $42.00 \mathrm{a}$ & $25.25 \mathrm{a}$ & $101.0 a^{*}$ \\
\hline $\mathrm{MC}$ & $13.00 \mathrm{a}$ & $20.67 \mathrm{a}$ & $32.00 \mathrm{a}$ & $37.66 \mathrm{a}$ & $25.83 a$ & $103.3 \mathrm{a}$ \\
\hline Çöğür & $5.33 \mathrm{C}$ & $7.33 \mathrm{~b}$ & $15.00 \mathrm{~b}$ & $21.33 b$ & $12.25 \mathrm{~b}$ & $49.0 \mathrm{~b}$ \\
\hline Ortalama & $9.67 d^{* *}$ & $15.44 \mathrm{c}$ & $25.67 \mathrm{~b}$ & $33.67 \mathrm{a}$ & & \\
\hline
\end{tabular}

*: Aynı sütunda aynı harfle gösterilen anaç ortalamaları arasındaki fark önemli değildir ( $P>0.05)$.

**: Aynı satırda aynı harfle gösterilen yıl ortalamaları arasındaki fark önemli değildir $(P>0.05)$
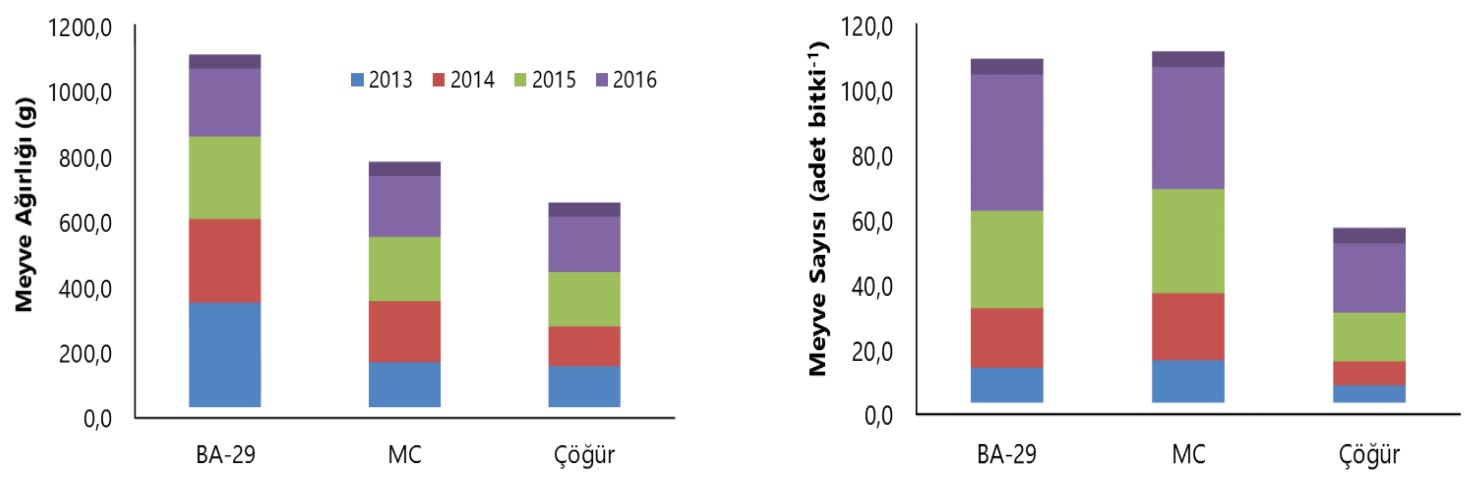

Şekil 1. 'Deveci' armut çeşidinde meyve ağırlığı (g) ve meyve sayısının (adet bitki ${ }^{-1}$ ) anaçlara ve yıllara göre değişimi.

Figure 1. Variation of fruit weight ( $g$ ) and fruit number (number plant ${ }^{-1}$ ) according to rootstocks and years in 'Deveci' pear cultivar.

Araştırmada en yüksek bitki başına ortalama meyve verimi BA-29 anacı üzerine aşlı bitkilerden $(6.09$ kg bitki$\left.{ }^{1}\right)$, en düşük ise çöğür (1.92 $\left.\mathrm{kg} \mathrm{bitki}^{-1}\right)$ üzerine aşılı bitkilerden elde edildiği tespit edilmiştir. Araştırma yılları arasında bitki başına verim bakımından farklılıkların olduğu, en yüksek bitki başına verimin 2016 yılında elde edildiği saptanmıştır. Bitki başına kümülatif verim üzerine anaçların önemli etkisinin olduğu saptanmış olup en yüksek bitki başına kümülatif verim BA-29 ayva klon anacı üzerine aşılı bitkilerden (24.36 kg bitki-1) en düşük ise armut çöğür anacı üzerine aşılı bitkilerden (7.67 kg bitki ${ }^{-1}$ ) elde edilmiştir (Çizelge 3).

Araştırmada bitki başına verim ve bitki başına kümülatif verim bitki başına meyve sayısı ve otalama meyve ağırlığıyla doğrudan ilişkili olarak değişmiştir. En yüksek bitki başına verim ve kümülatif verimin elde edildiği anaç üzerine aşılı bitkilerde ortalama meyve ağırlığının (Çizelge 1) ve bitki başına meyve sayısının da (Çizelge 2) yüksek olduğu görülmüştür. 
Çizelge 3. 'Deveci' armut çeşidinde anaçların bitki başına verim (kg bitki $\left.{ }^{-1}\right)$ üzerine etkileri.

Table 3. The effect of rootstocks on yield per plant $\left(\mathrm{kg} \mathrm{plant}^{-1}\right)$ of 'Devecei' pear cultivar.

\begin{tabular}{|c|c|c|c|c|c|c|}
\hline \multirow{2}{*}{ Anaçlar } & \multicolumn{4}{|c|}{ Yıllar } & \multirow[b]{2}{*}{ Ortalama } & \multirow[b]{2}{*}{ Kümülatif verim $\left(\mathrm{kg} \mathrm{bitki}^{-1}\right)$} \\
\hline & 2013 & 2014 & 2015 & 2016 & & \\
\hline BA-29 & $3.40 \mathrm{a}$ & $4.69 \mathrm{a}$ & $7.58 \mathrm{a}$ & $8.68 \mathrm{a}$ & $6.09 \mathrm{a}$ & $24.36 a^{*}$ \\
\hline $\mathrm{MC}$ & $1.79 \mathrm{~b}$ & $3.81 \mathrm{~b}$ & $6.29 \mathrm{a}$ & $7.01 \mathrm{~b}$ & $4.73 \mathrm{~b}$ & $18.91 b$ \\
\hline Çöğür & $0.67 c$ & $0.90 \mathrm{c}$ & $2.49 \mathrm{~b}$ & $3.61 \mathrm{c}$ & $1.92 \mathrm{c}$ & $7.67 \mathrm{c}$ \\
\hline Ortalama & $1.95 d^{\star *}$ & $3.13 c$ & $5.46 \mathrm{~b}$ & $6.43 a$ & & \\
\hline
\end{tabular}

*: Aynı sütunda aynı harfle gösterilen anaç ortalamaları arasındaki fark önemli değildir $(P>0.05)$.

$\star *$ : Aynı satırda aynı harfle gösterilen yıl ortalamaları arasındaki fark önemli değildir $(P>0.05)$.

Bitki başına verimin BA29 üzerine aşılı 'Deveci' armut çeşidinde 5920.0-6313.0 g (Erdem ve Öztürk, 2012), 5420.0-7782.0 g (Küçüker ve ark., 2015) arasında değiştiği bildirilmiştir. Araştırma yıllarına ve yapılan uygulamalara bağlı olarak bitki başına meyve veriminin değiştiğini vurgulayan Uysal ve ark. (2015) BA-29 üzerine aşlı 'Deveci' armut çeşidinde bitki başına verimin 2010 yılında 5252.0-7150.0 g, 2011 yılında 10954.0-12778.0 g arasında olduğunu saptamışlardır. BP1, BP3 armut ve Quince A ayva klon anacı üzerine aşılı 'Forelle' armut çeşidinde bitki başına verimin ayva klon anacında en yüksek olduğu, bitki başına kümülatif verimin 3.7-24.4 kg ağaç-1 olduğu belirlenmiştir (du Plooy ve van Huyssteen, 2000). Farklı anaçlar üzerine aşılı 'Williams' armut çeşidinde bitki başına verimin yıllara ve anaçlara göre, bitki başına kümülatif verimin de anaçlara göre değişim gösterdiği tespit edilmiş olup OHxF333 anacının kümülatif veriminin diğer anaçlardan daha yüksek olduğu belirtilmiştir (Urbina ve ark., 2003). Stern ve Doron (2009) farkı ayva ve armut anaçları üzerine aşılı 'Coscia' armut çeşidinde bitki başına verim ve bitki başına kümülatif verim üzerine anaçların etkisinin önemli olduğunu bildirmiş olup bitki başına kümülatif verimin 16.8-61.6 kg ağaç-1 olduğunu belirlemişlerdir. Cabrera ve ark. (2015) 'Williams' armudunda 2003-2013 yılları arasındaki ortalama ağaç başına verimin $64-134 \mathrm{~kg}$ arasında değiştiğini ve bitki başına en yüksek verimin BA-29 ayva klon anacından elde edildiğini bildirmişlerdir. Farklı ayva ve armut anaçları üzerine aşılı 'Santa Maria' armut çeşidinde bitki başına verimin araştırmanın ilk yıllarında ayva klonlarında daha yüksek, ilerleyen yıllarında ise armut çöğür anacında daha yüksek olduğu vurgulanmıştır (ikinci ve ark., 2014). Meszaros ve ark. (2019) 'Alexander Lucas', 'Conference' ve 'Red Bartlett' armut çeşitlerinde bitki başına verim ile bitki başına kümülatif verimin hem anaçlara hem de çeşitlere göre farklılık gösterdiğini bildirmişlerdir. Farklı ayva ve armut anaçları üzerine aşılı 'Shahmiveh' armut çeşidinde bitki başına verim üzerine anaçların ve araştırma yıllarının etkisinin önemli olduğunu vurgulayan Askari-Khorosgani ve ark. (2019) bitki başına en yüksek verimin BA-29 (41.3 kg) ve Quince A $(39.6 \mathrm{~kg})$ anaçlarından elde edildiğini bildirmişlerdir. Araştırmadan elde edilen sonuçları benzer konularda yapılan diğer çalışmalar ile (Urbina ve ark., 2003; Iglesias ve Asin, 2005; Stern ve Doron, 2009; İinci ve ark., 2014; Askari-Khorosgani ve ark., 2019) uyumlu olduğu, ortaya çıkan farklılıkların ise kullanılan anaç, çeşit ve ekolojiden kaynaklandığı söylenebilir.

Araştırmada değişik anaçların 'Deveci' armut çeşidinin gövde kesit alanına düşen verim üzerine önemli etkisinin olduğu tespit edilmiştir. En yüksek gövde kesit alanına düşen verim $\mathrm{MC}$ ayva klon anacı üzerine aşılanan bitkilerde $\left(0.69 \mathrm{~kg} \mathrm{~cm}^{-2}\right)$ tespit edilirken, en düşük ise armut çöğür anacı üzerine aşılı bitkilerde $\left(0.22 \mathrm{~kg} \mathrm{~cm}^{-2}\right)$ tespit edilmiştir (Çizelge 4).

Çizelge 4. 'Deveci' armut çeşidinde anaçların gövde kesit alanına verim $\left(\mathrm{kg} \mathrm{cm}^{-2}\right)$ üzerine etkileri. Table 4. The effect of rootstocks on yield per plant cross sectional area $\left(\mathrm{kg} \mathrm{cm}^{-2}\right)$ of 'Devecei' pear cultivar.

\begin{tabular}{lllllll}
\hline \multirow{2}{*}{ Anaçlar } & \multicolumn{9}{c}{ Yıllar } & Ortalama & $\begin{array}{l}\text { Kümülatif gövde kesit } \\
\left.\text { alanına verim (kg } \mathbf{~ c m}^{-2}\right)\end{array}$ \\
\cline { 2 - 5 } & $\mathbf{2 0 1 3}$ & $\mathbf{2 0 1 4}$ & $\mathbf{2 0 1 5}$ & $\mathbf{2 0 1 6}$ & & $1.33 \mathrm{~b}^{\star}$ \\
BA-29 & $0.25 \mathrm{a}$ & $0.26 \mathrm{~b}$ & $0.47 \mathrm{~b}$ & $0.34 \mathrm{~b}$ & $0.33 \mathrm{~b}$ & $2.75 \mathrm{a}$ \\
ÇC & $0.33 \mathrm{a}$ & $0.62 \mathrm{~b}$ & $0.91 \mathrm{a}$ & $0.90 \mathrm{a}$ & $0.69 \mathrm{a}$ & $0.90 \mathrm{c}$ \\
\hline Ortalama & $0.16 \mathrm{a}$ & $0.12 \mathrm{a}$ & $0.30 \mathrm{~b}$ & $0.32 \mathrm{~b}$ & $0.22 \mathrm{c}$ & \\
\hline
\end{tabular}

*: Aynı sütunda aynı harfle gösterilen anaç ortalamaları arasındaki fark önemli değildir $(P>0.05)$.

**: Aynı satırda aynı harfle gösterilen yıl ortalamaları arasındaki fark önemli değildir $(P>0.05)$.

Araşıırma yılları arasında gövde kesit alanına düşen verim bakımından farklııklar tespit edilmiş olup 2015 ve 2016 yılı verimlerinin 2013 ve 2014 yılı verimlerinden daha yüksek olduğu saptanmıştır. Araştırmada gövde kesit alanına düşen kümülatif verimin $\mathrm{MC}$ ayva klon anacı üzerine aşılı bitkilerde en yüksek $\left(2.75 \mathrm{~kg} \mathrm{~cm}^{-2}\right)$, armut çöğür anacı üzerine aşılı bitkilerde ise en düşük $\left(0.90 \mathrm{~kg} \mathrm{~cm}^{-2}\right)$ olduğu belirlenmiştir (Çizelge 4). Gövde kesit alanına düşen verim üzerine anaçların etkisinin önemli olduğu yapılan benzer çalışmalarda vurgulanmıştır (du Plooy ve van Huyssteen, 2000; Urbina ve ark., 2003; Iglesias ve Asin, 2005; Stern ve Doron, 2009; Pasa ve ark., 2017; Askari- 
Khorosgani ve ark., 2019). Farklı anaçlar üzerine aşılı 'Forelle' armut çeşidinin gövde kesit alanına düşen verimi üzerine kullanılan anaçların etkisinin önemli olduğu ve Quince A ayva klon anacı üzerine aşılı bitkilerin gövde kesit alanına düşen verimlerinin armut anaçlarından daha yüksek olduğu bildirilmiştir (du Plooy ve van Huyssteen, 2000). Ayva ve armut klon anaçları ile armut çöğür anacı üzerine aşılı 'Conference' armut çeşidinde gövde kesit alanına düşen verim üzerine anaçların etkisinin önemli olduğunu vurgulayan Iglesias ve Asin, (2005) gövde kesit alanına düşen verimin en yüksek EMC anacından elde edildiğini bildirmiştir. Ayva ve armut anaçları üzerine aşıı 'Coscia' armut çeşidinde gövde kesit alanına düşen verimin $0.83-1.45 \mathrm{~kg} \mathrm{~cm}^{-2}$ arasında değiştiğini bildiren Stern ve Doron (2009) armut anaçlarına göre ayva anaçlarının gövde kesit alanına düşen verimlerinin daha yüksek olduğunu belirtmişlerdir. Pasa ve ark., (2017) farklı ayva klon anaçları üzerine aşılı 'Carrick' armut çeşidinde yıllara göre değişmekle birlikte gövde kesit alanına düşen verimin $0.014-0.156 \mathrm{~kg} \mathrm{~cm}^{-2}$ olduğunu bildirmiş olup kümülatif gövde kesit alanına düşen verimin MC ve Portugal anaçlarında en yüksek olduğunu vurgulamışlardır. Farklı anaçlar üzerine aşılı 'Shahmiveh' armut çeşidinde gövde kesit alanına düşen verimin 0.1-3.0 kg cm${ }^{-2}$ arasında değiştiği bildirilmiştir (Askari-Khorosgani ve ark., 2019). 'Alexander Lucas', 'Conference' ve 'Red Bartlett' armut çeşitlerinde gövde kesit alanına düşen verimin araştırma yılı, anaç ve çeşitlere göre farklılık gösterdiğini bildiren Meszaros ve ark. (2019) armut anaçlarına göre ayva anaçlarının gövde kesit alanına düşen verimlerinin daha yüksek olduğunu saptamışlardır. Araştırmamızda ayva anaçlarının gövde kesit alanına düşen veriminin armut çöğür anacından daha yüksek olduğu belirlenmiştir. Ayrıca ayva klon anaçları içerisinde de en zayıf (bodur) gelişme gösteren $\mathrm{MC}$ anacının BA-29 ayva klon anacından daha yüksek gövde kesit alanına sahip olduğu saptanmıştır. Araştırmada bitki başına verim ile gövde kesit alanına düşen verimin ters orantılı olarak değiştiği saptanmıştır. Anacın gelişme kuvvetine (gövde kesit alanına) bağlı olarak bitki başına verimin yüksek olduğu anaçlarda gövde kesit alanına düşen verimin düşük olduğu tespit edilmiştir (Şekil 2). Bu durum anaçların gelişme kuvvetlerinin farklı olmasından kaynaklanmaktadır (Jackson, 2003). Nitekim Pasa ve ark. (2017) daha zayıf gelişme gücüne sahip olan MC ve Portugal anaçlarının kuvvetli gelişme gösteren anaçlara göre gövde kesit alanlarının düşük ancak gövde kesit alanlarına düşen verimlerinin yüksek olduğunu bildirmişlerdir. Benzer şekilde 'Conference' ve 'Doyenne du Comice' armut çeşitlerinde gövde kesit alanına düşen en yüksek verim zayıf gelişen $M C$ anacı üzerinde tespit edilmiştir (Maas, 2008). Bu etkilerin anaçların vejetatif gelişme ve verim arasındaki rekabetinde meydana gelen azalma ile açıklanabileceği ifade edilmiştir (Smith ve Smach, 2013). Meyvelerin sürgünlere göre daha fazla besin tükettiği göz önüne alınırsa bodur anaçların üzerindeki meyveler gelişmeyi de zayıflatmakta ve bu sayede sürgün gelişmesi de zayıf olmaktadır. Bu durum bitkinin üretmiş olduğu besin rezervini artırmakta buda meyve tutumu artırmaktadır (Pasa ve ark., 2017). Buna ilave olarak bodur bir anaç, meyve ile vejetatif büyümenin daha az rekabetine neden olacak ve iklim koşullarının olumsuzluklarını ortadan kaldırmak için karbonhidrat rezervini artırmaya çalışacaktır. Araştırmadan elde edilen sonuçların benzer konularda yapılan önceki çalışmalarla uyumlu olduğu görülmektedir.
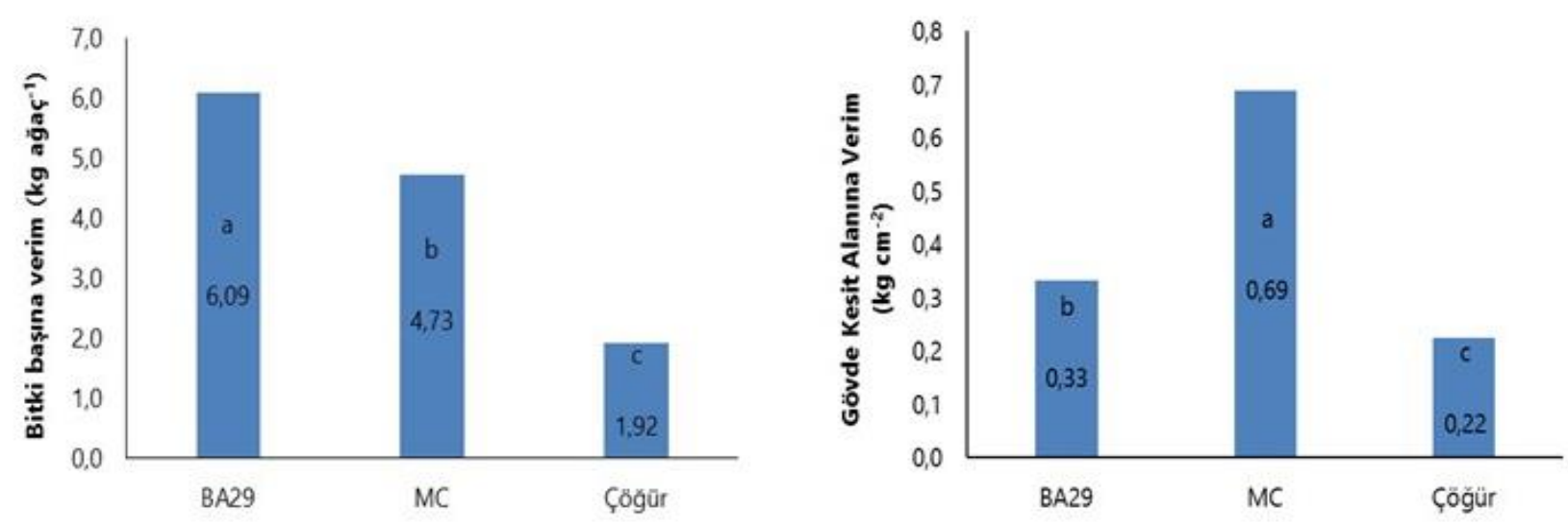

Şekil 2. 'Deveci' armut çeşidinde bitki başına verim $\left(\mathrm{kg}\right.$ bitki $\left.{ }^{-1}\right)$ ve gövde kesit alanına düşen verimin $\left(\mathrm{kg} \mathrm{cm}^{-2}\right)$ anaçlara ve yıllara göre değişimi.

Figure 2. Variation of yield per plant $\left(\mathrm{kg} \mathrm{plant}^{-1}\right)$ and yield per stem cross-sectional area $\left(\mathrm{kg} \mathrm{cm}^{-2}\right)$ in 'Deveci' pear variety by rootstocks and years.

Farklı anaçların 'Deveci' armut çeşidinin taç hacmine düşen verim üzerine istatistiksel olarak önemli etkisinin olduğu tespit edilmiştir. En yüksek taç hacmine düşen verim MC ayva klon anacı üzerine aşılanan bitkilerde (7.22 $\mathrm{kg} \mathrm{cm}^{-3}$ ) tespit edilirken, en düşük ise armut çögür anacı ve BA-29 ayva klon anacı üzerine aşlı bitkilerde (2.14 kg $\mathrm{cm}^{-3}$ ve $2.74 \mathrm{~kg} \mathrm{~cm}^{-3}$ ) tespit edilmiştir (Çizelge 5). 
Çizelge 5. 'Deveci' armut çeşidinde anaçların taç hacmine düşen verim $\left(\mathrm{kg} \mathrm{m}^{-3}\right)$ üzerine etkileri. Table 5. The effect of rootstocks on yield per canopy volume $\left(\mathrm{kg} \mathrm{m}^{-3}\right)$ of 'Devecei' pear cultivar.

\begin{tabular}{|c|c|c|c|c|c|c|}
\hline \multirow{2}{*}{ Anaçlar } & \multicolumn{4}{|c|}{ Yıllar } & \multirow{2}{*}{ Ortalama } & \multirow{2}{*}{$\begin{array}{l}\text { Kümülatif Taç Hacmine } \\
\text { Verim }\left(\mathbf{k g ~ m}^{-3}\right)\end{array}$} \\
\hline & 2013 & 2014 & 2015 & 2016 & & \\
\hline BA-29 & $1.86 \mathrm{~b}$ & $2.37 \mathrm{~b}$ & $3.49 \mathrm{~b}$ & $3.22 b$ & $2.74 \mathrm{~b}$ & $10.94 b^{*}$ \\
\hline $\mathrm{MC}$ & $3.83 a$ & $7.60 \mathrm{~b}$ & $7.91 \mathrm{a}$ & $9.56 \mathrm{a}$ & $7.22 \mathrm{a}$ & 28.91 a \\
\hline Çöğür & $1.10 \mathrm{~b}$ & $1.05 \mathrm{a}$ & $2.74 \mathrm{~b}$ & $3.67 b$ & $2.14 \mathrm{~b}$ & $8.56 \mathrm{~b}$ \\
\hline Ortalama & $2.26 c^{* *}$ & $3.67 \mathrm{~b}$ & $4.71 \mathrm{ab}$ & $5.48 \mathrm{a}$ & & \\
\hline
\end{tabular}

*: Aynı sütunda aynı harfle gösterilen anaç ortalamaları arasındaki fark önemli değildir $(P>0.05)$.

**: Aynı satırda aynı harfle gösterilen yıl ortalamaları arasındaki fark önemli değildir $(P>0.05)$

Araştırma yılları arasında taç hacmine düşen verim bakımından farklılıklar tespit edilmiş olup 2016 yılı taç hacmine verimin en yüksek $\left(5.48 \mathrm{~kg} \mathrm{~cm}^{-3}\right), 2013$ yılı veriminin ise en düşük $\left(2.26 \mathrm{~kg} \mathrm{~cm}^{-3}\right)$ olduğu saptanmıştır. Araştırmada taç hacmine düşen kümülatif verimin $M C$ ayva klon anacı üzerine aşılı bitkilerde $\left(28.91 \mathrm{~kg} \mathrm{~cm}^{-3}\right)$ armut çöğür anacı ve BA-29 ayva klon anacı üzerine aşılı bitkilerden $\left(8.56 \mathrm{~kg} \mathrm{~cm}^{-3} \mathrm{ve} 10.94 \mathrm{~kg} \mathrm{~cm}^{-3}\right)$ daha yüksek olduğu tespit edilmiştir (Çizelge 5). Araştırmada büyüme gücü daha zayıf olan $\mathrm{MC}$ anacını taç hacmini diğer anaçlara göre daha küçük olduğu gözlemlenmiştir. Her ne kadar bitki başına verim MC anacında BA-29 anacına göre düşük olsa da taç hacminin küçük olması dolayısıyla birim taç hacmine verim bu anaçta en yüksek olmuştur.

Araştırmada değişik anaçların 'Deveci' armut çeşidinde dekara verim üzerine önemli etkisinin olduğu tespit edilmiştir. En yüksek dekara verim BA-29 ayva klon anacı üzerine aşılı bitkilerden (733.85 kg da-1) elde edilirken, en düşük ise armut çöğür anacı üzerine aşılı bitkilerden (118.88 $\left.\mathrm{kg} \mathrm{da}^{-1}\right)$ elde edilmiştir. Araştırma yılları arasında dekara verim bakımından önemli farklılıklar tespit edilmiştir. En yüksek dekara verim 2014 yılında (693.28 kg da$\left.{ }^{1}\right)$, en düşük ise 2015 yılında (338.34 $\mathrm{kg} \mathrm{da}^{-1}$ ) belirlenmiştir (Çizelge 6).

Çizelge 6. 'Deveci' armut çeşidinde anaçların dekara verim $\left(\mathrm{kg} \mathrm{da}^{-1}\right)$ üzerine etkileri.

Table 6. The effect of rootstocks on yield per decare $\left(\mathrm{kg} \mathrm{da}^{-1}\right)$ of 'Devecei' pear cultivar.

\begin{tabular}{|c|c|c|c|c|c|c|}
\hline \multirow{2}{*}{ Anaçlar } & \multicolumn{4}{|c|}{ Yıllar } & \multirow{2}{*}{ Ortalama } & \multirow{2}{*}{ Kümülatif verim $\left(\mathrm{kg} \mathrm{da}^{-1}\right)$} \\
\hline & 2013 & 2014 & 2015 & 2016 & & \\
\hline BA-29 & 810.26 a & $1.116 .86 \mathrm{a}$ & $470.12 a$ & $538.15 a$ & 733.85 a & $2.935 .40 a^{*}$ \\
\hline $\mathrm{MC}$ & $425.46 \mathrm{~b}$ & $907.40 \mathrm{~b}$ & 390.25 a & $434.51 \mathrm{~b}$ & $539.41 b$ & $2.160 .34 \mathrm{~b}$ \\
\hline Çöğür & $41.36 \mathrm{c}$ & $55.59 \mathrm{c}$ & $154.64 \mathrm{~b}$ & $223.91 \mathrm{c}$ & $118.88 \mathrm{c}$ & $475.50 \mathrm{c}$ \\
\hline Ortalama & $425.69 b^{* *}$ & 693.28 a & $338.34 \mathrm{c}$ & $398.86 \mathrm{~b}$ & & \\
\hline
\end{tabular}

*: Aynı sütunda aynı harfle gösterilen anaç ortalamaları arasındaki fark önemli değildir ( $P>0.05)$.

**: Aynı satırda aynı harfle gösterilen yıl ortalamaları arasındaki fark önemli değildir $(P>0.05)$

Araştırmada kümülatif verimin $\left(\mathrm{kg} \mathrm{da}^{-1}\right)$ BA-29 ayva klon anacı üzerine aşılı bitkilerde en yüksek (2935.40 kg $\left.\mathrm{da}^{-1}\right)$, armut çöğür anacı üzerine aşılı bitkilerde ise en düşük $\left(475.50 \mathrm{~kg} \mathrm{da}^{-1}\right)$ olduğu saptanmıştır (Çizelge 6). 'Forelle' armut çeşidinin verimi üzerine kullanılan anaçların ve üretim yıllarının etkisinin olduğu belirlenmiş ve hektara kümülatif verimin 5.4-69.7 ton olduğu saptanmıştır (du Plooy ve van Huyssteen, 2000). Ayva klon anaçları üzerine aşılı 'Carrick' armut çeşidinde verimin anaçlara göre değiştiğini ifade eden Pasa ve ark. (2017) verimin 4062 ton ha-1 olduğunu bildirmişlerdir. Benzer şekilde BA-29 üzerine aşılı 'Rocha' armut çeşidinde verimin üretim yıllarına göre değiştiğini bildiren Sete ve ark. (2019) verimin 11.9-16.3 ton ha ${ }^{-1}$ olduğunu tespit etmişlerdir. Farklı anaçlar üzerine aşılı 'Santa Maria' armut çeşidinde hektara verimin en yüksek BA-29 ve MC anaçlarından en düşük ise armut çöğür anacından elde edildiğini bildiren İkinci ve ark. (2014) ayva anaçlarının veriminin armut çöğür anacından daha yüksek olduğunu bildirmiştir. Araştırmamızda BA-29 üzerine aşıı bitkilerin dekara veriminin diğer anaçlardan daha yüksek olduğu saptanmıştır. Bu durum ayva anaçlarının armut çöğür anacına göre verime daha erken başlamaları (Jackson, 2003) ve dikimi takip eden ilk yıllarda daha hızlı gelişme göstermeleri (Öztürk ve Öztürk, 2014), su ve besin maddelerinden daha iyi yararlanmalarından kaynaklanabilir. Nitekim BA29 ayva klon anacı üzerine aşılanan bitkilerin meyve veriminin diğer anaçlardan daha yüksek olmasını anacın su ve besin maddelerini alma potansiyelinin diğer anaçlardan daha yüksek olmasına bağlı olduğu ifade edilmiştir (AskariKhorosgani ve ark. (2019). Araştırmadan elde edilen sonuçlar ile önceki çalışmaların sonuçlarının uyumlu olduğu, ortaya çıkan farklııkların, anaç, çeşit, yetiştirme tekniği ve ekolojik farklııklardan kaynaklandığı söylenebilir.

\section{SONUÇ}

Farklı anaçların 'Deveci' armut çeşidinin meyve verim özellikleri üzerine etkisinin incelendiği bu çalışmada anaçların verim özellikleri üzerine önemli etkisinin olduğu saptanmıştır. Araştırmada meyve ağırlığı (g), bitki başına 
kümülatif meyve sayısı (adet bitki $\left.{ }^{-1}\right)$, bitki başına verim $\left(\mathrm{kg} \mathrm{bitki}^{-1}\right)$, ve dekara verim $\left(\mathrm{kg} \mathrm{da}^{-1}\right) \mathrm{BA}-29$ ayva klon anacında en yüksek iken gövde kesit alanına verim $\left(\mathrm{kg} \mathrm{cm}^{-2}\right)$ ve taç hacmine verimin $\left(\mathrm{kg} \mathrm{m}^{-3}\right) \mathrm{MC}$ ayva klon anacı üzerine aşılı bitkilerde daha yüksek olduğu belirlenmiştir. Araştırmanın yürütüldüğü 2013-2016 yılları arasında armut çöğür anacı üzerine aşılı bitkilerin verim özelliklerinin ayva anaçlarından daha düşük olduğu saptanmıştır. Özellikle dekara verimin BA-29 ayva klon anacında diğer anaçlardan daha yüksek olması dolayısıyla üreticinin elde edecek olduğu gelirde yüksek olacaktır. Gövde kesit alanına verimin yüksek olduğu $M C$ anacı daha sık dikim bahçeler için önerilebilir. Araştırmanın yürütüldüğü süreler içerisinde ayva anaçlarından BA-29'un verim özellikleri bakımından daha iyi olduğu sonucuna varılmıştır. Ayrıca araştırmanın daha uzun süre devam ettirilerek anaçların kıyaslanması tavsiye olunmaktadır.

\section{ÇIKAR ÇATIŞMASI}

Yazar herhangi bir çıkar çatışması olmadığını bildirmektedir.

\section{YAZAR KATKISI}

Makalenin tüm aşamaları yazar tarafından gerçekleştirilmiştir.

\section{KAYNAKLAR}

Askari-Khorasgani, O., Jafarpour, M., Hadad, M. M., \& Pessarakli, M. (2019). Fruit yield and quality characteristics of "Shahmiveh" pear cultivar grafted on six rootstocks, Journal of Plant Nutrition, 42(4), 323-332,

Bell, R. L., Quamme, H. A., Layne, R. E. C., \& Skirvin, R. M. (1996). Pears. In J. Janick, \& J. N. Moore (Eds.). Fruit Breeding; Volume I: Tree and Tropical Fruits. Wiley Science, New York.

Browning, G., \& Watkins, R. (1991). Preliminary evaluation of new quince (Cydonia oblonga Miller) hybrid rootstocks for pears. Journal Horticultural Science and Biotechnology, 66, 35-42.

Cabrera, D., Rodriquez, P., \& Zoppolo, R. (2015). Evaluation of Quince and Selected 'Farold ®' Pear Rootstocks for Commercial 'Williams B.C.' Production in Uruguay. Acta Horticulturae, 1094, 159-162.

Du Plooy, P., \& van Huyssteen, P. (2000). Effect of BP1, BP3 and Quince A rootstocks, at three planting densities, on precocity and fruit quality of 'Forelle' pear (Pyrus communis L.), South African Journal of Plant and Soil, 17(2), 57-59.

Ercisli, S. (2004). A short review of the fruit germplasm resources of Turkey. Genetic Resource Crop Evoluation, 51, 419-435.

Erdem, H., \& Öztürk, B. (2012). Yapraktan Uygulanan Çinko'nun BA-29 Anacı Üzerine Aşılı Armut Çeşitlerinin Verimi, Mineral Element İçeriği ye Biyokimyasal Özellikleri Üzerine Etkisi. Süleyman Demirel Üniversitesi Ziraat Fakültesi Dergisi, 7(1), 93106.

FAO. (2021). Food and Agriculture Organization of the United Nations. Statistics of Crops and livestock products. http://faostat.fao.org/site/567/DesktopDefault.aspx?PagelD=567\#ancor. Erişim tarihi: 15 Temmuz 2021.

Francescatto, P., Pazzin, D., Neto, A. G., Fachinello, J. C., \& Giacobbo, C. L. (2010). Evaluation of graft compatibility between quince rootstocks and pear scions. Acta Horticulturae, 872, 253-259.

Hancock, J. F., \& Lobos, G. A. (2008). Pears. In J. F. Hancock (Ed.). Temperate Fruit Crop Breeding: Germplasm to Genomics, Springer, New York.

Iglesias, I., \& Asin, L. (2005). Performance of 'Conference' Pear on Self-rooted Trees and Several Old Home $\times$ Farmingdale, Seedling and Quince Rootstocks in Spain. Acta Horticulturae, 671, 485-491.

Iglesias, I., \& Asin, L. (2011). Agronomical Performance and Fruit Quality of 'Conference' Pear Grafted on Clonal Quince and Pear Rootstocks. Acta Horticulturae, 903, 439-442.

İkinci, A., Bolat, I., Ercisli, S., \& Kodad, O. (2014). Influence of rootstocks on growth, yield, fruit quality and leaf mineral element contents of pear cv. 'Santa Maria' in semi-arid conditions. Biological Research, 47(71), 1-8.

Jackson, J. E. (2003). Biology of Apples and Pears. Cambridge University, USA.

Kosina, J. (2003). Evaluation of pear rootstocks in an orchard. Horticultural Science (Prague), 30(2), 56-58.

Küçüker, E., Öztürk., B., Özkan, Y., \& Yıldız, K. (2015). Yapraktan Üre Uygulamasının Farklı Armut (Pyrus communıs L.) Çeşitlerinde Verim, Meyve Kalitesi ve Bioaktif Bileşikler Üzerine Etkisi. Niğde Üniversitesi Mühendislik Bilimleri Dergisi, 4(2), 78-86. 
Maas, F. (2008). Evaluation of Pyrus and quince rootstocks for high density pear orchards. Acta Horticulturae, 800, 599-609.

Meszaros, M., Lanar, L., Kosina, J., \& Namestek, J. (2019). Aspects influencing the rootstock-scion performance during long term evaluation in pear orchard. Horticultural Science (Prague), 46(1), 1-8.

MGM, (2021). Meteoroloji Genel Müdürlüğü. https://www.mgm.gov.tr/tahmin/il-ve-ilceler.aspx?m=SAMSUN\#/. Erişim tarihi: 10 Temmuz 2021.

Özçağıran, R., Ünal, A., Özeker, E., \& İsfendiyaroglu, M. (2005). Armut. Ilıman Iklim Meyve Türleri (Yumuşak Çekirdekli Meyveler), Ege Üniversitesi Ziraat Fakültesi Yayınları, Yayın No: 556, Bornova-İzmir, Türkiye,

Öztürk, A., \& Öztürk, B. (2014). The rootstock influences growth and development of 'Deveci' Pear. Turkish Journal of Agriculture and Natural Science, 1, 1049-1053.

Pasa, M. S., Schmitz, J. D., Silva, C. D., \& Giovanaz, M. A. (2017). Performance of 'Carrick' pear grafted on quince rootstocks. Agropecuaria Catarinense, Florianopolis, 30(1), 57-60.

Sete, P. B., Comin, J. J., Ciotta, M. N., Salume, J. A., Thewes, T., Brackmann, A., Toselli, M., Nava, G., Rozane, D. E., Loss, A., Lourenzi, C. R., Couto, R. R., \& Brunetto, G. (2019). Nitrogen fertilization affects yield and fruit quality in pear. Scientia Horticulturae, 258, 108782.

Smıth, H. M., \& Samach, A. (2013). Constraints to obtaining consistent annual yields in perennial tree crops. I: Heavy fruit load dominates over vegetative growth. Plant Science, 207, 158-167.

Stern, R. A, \& Doron, I. (2009). Performance of 'Coscia' pear (Pyrus communis) on nine rootstocks in the north of Israel. Scientia Horticulturae, 119, 252-256.

TÜiK. (2021). Türkiye İstatistik Kurumu. Bitkisel Üretim İstatistikleri. https://biruni.tuik.gov.tr/medas/?locale=tr. Erişim tarihi: 15 Temmuz 2021.

Urbina, V., Dalmases, J., Pascual, M., \& Dalmau, R. (20039. Performance of 'Williams' pear on five rootstocks. Journal of Horticultural Science \& Biotechnology, 78(2), 193-196.

Uysal, E., Sağlam, M. T., \& Büyükyılmaz, M. (2015). Deveci Armut Çeşidinde Farklı Azot Uygulamalarının Verim ve Bazı Kalite Özellikleri Üzerine Etkisi. Bahçe, 44(1), 1 - 13.

Webster, A. D. (1998). A brief review of pear rootstock development. Acta Horticulturae, 475, 135-142.

Webster, T. (2002). Dwarfing rootstocks: past, present and future. Compact Fruit Tree, 35, 67-72. 